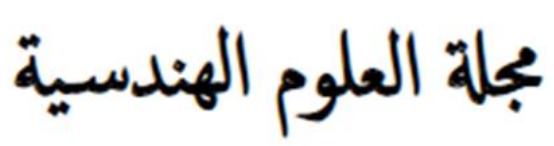

\title{
نمذجة أثر تغيُر سعر الصرف على أسعار الأسمنت في السودان (2000-
}

\section{(2016}

\author{
Mogahid Bilal Taha ${ }^{1, *}$, and Mudathir Suliman M.Ali ${ }^{1}$ \\ 1 Civil Engineering Department, University of Khartoum, Khartoum, Sudan \\ * Corresponding author: Mogahid Bilal Taha (Mogahid_b@hotmail.com).
}

Article history: Received 14 March 2020, Received in revised form 4 November 2020, Accepted 11 November 2020

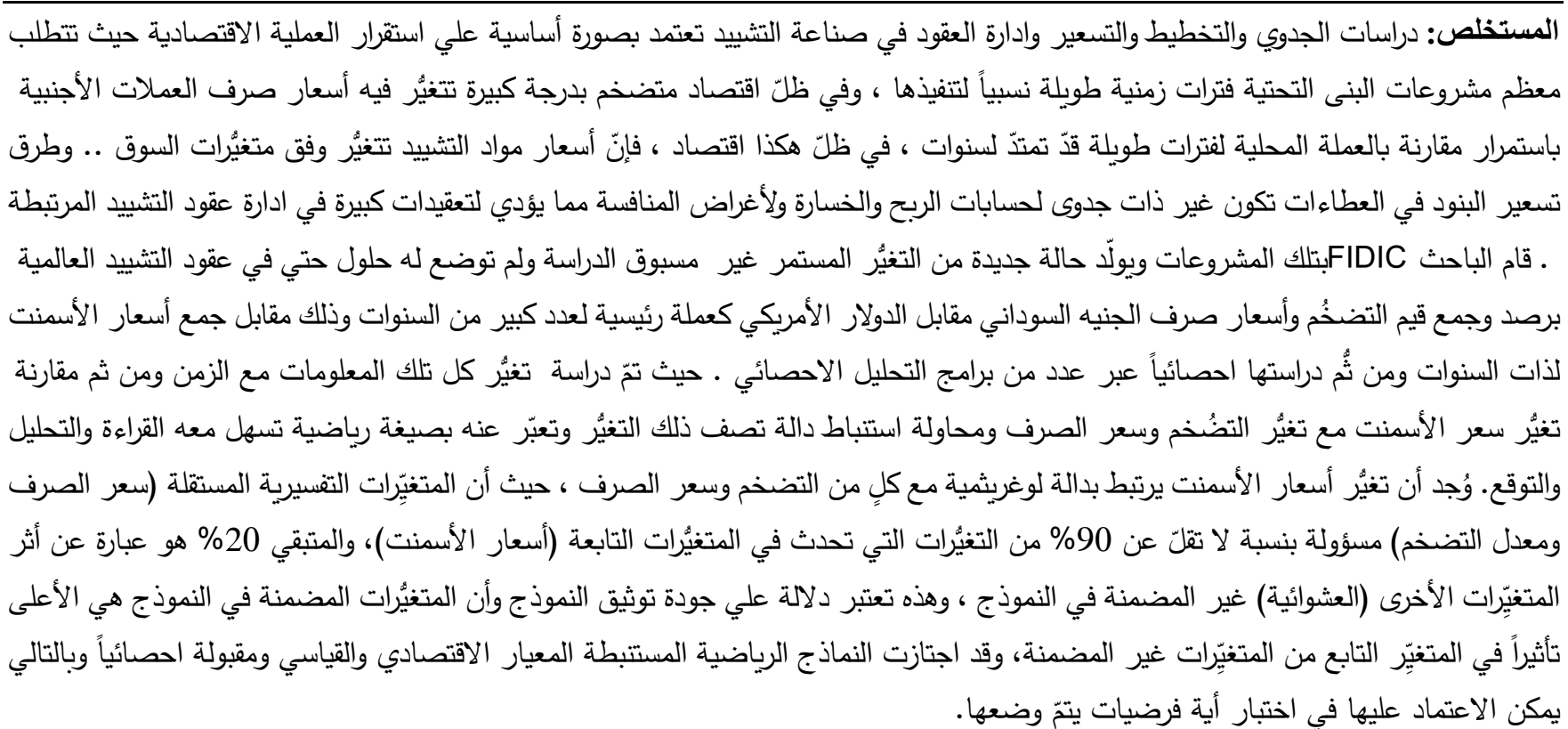

ABSTRACT Feasibility studies, planning, pricing and contract management in the construction industry depend mainly on the stability of the economic process where most infrastructure projects require relatively long periods of time to implement them. In a highly inflationary economy where foreign exchange rates constantly change compared to the local currency for long periods that may extend for years. In such an economy, the prices of construction materials vary according to market variables. The methods of pricing items in bids are not feasible for profit and loss accounts and for competition purposes, which leads to significant complications in the management of construction contracts associated with these projects and generates a new case of continuous change unprecedented and has not been resolved even in the global construction contracts of FIDIC. The researcher monitored and collected the inflation values and the exchange rate of Sudanese pound against US dollar as the main currency for a large number of years against the prices of cement for the same years and then statistically studied through a number of statistical analysis programs. Information has been studied over time and then the change in the price of cement versus inflation and the exchange rate and a try to devise a function has been carried out in order to describe that change and express it in a mathematical formula that facilitates reading, analyzing and forecasting. It was found that the change of cement prices is related in a logarithmic function with both inflation and the exchange rate. The independent explanatory variables (exchange rate and inflation rate) were found to be responsible for at least $80 \%$ of the changes in the dependent variables (cement prices). The remaining $20 \%$ is the impact of other (random) variables not included in the model, and this is an indication of the quality of the documentation of the model. That the variables included in the model is the most influential in the 
dependent variable of non-included variables. The mathematical models have passed derived economic and standard criterion and have been acceptable statistically and can therefore be relied upon to test any hypotheses are developed.

Keyword: construction industry, FIDIC, Feasibility studies, pricing and contract management

مما تقدم ، فإن مسألة ما هي قيمة واتجاه وأثر التضخم في قطاع البناء في

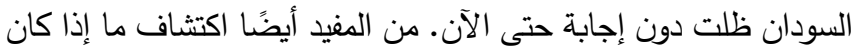

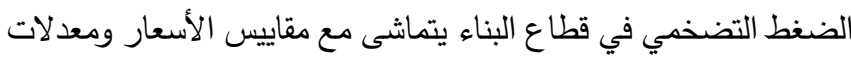

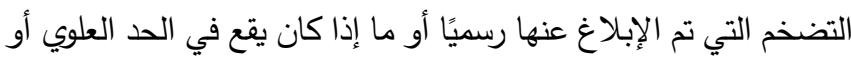

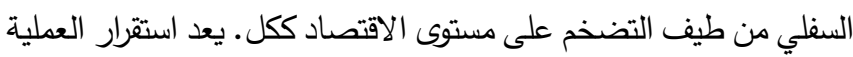

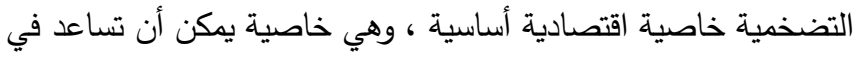

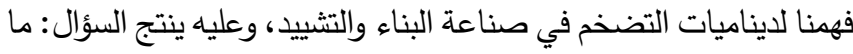
هي المعرفة الأساسية التي ستعزز قدرتنا على توضيح تحليل قضايا التضخم في صناعة البناء والتشييد؟ تتناول هذه الورقة ظاهرة التضخم الأساسية وحدوثها في قطاع البناء

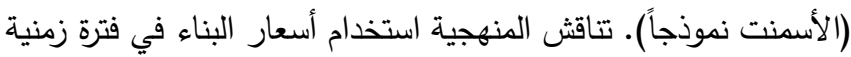
مقارنة مع نفس بيانات الفترة من التضخم وسعر الصرف في السودان لتوفير

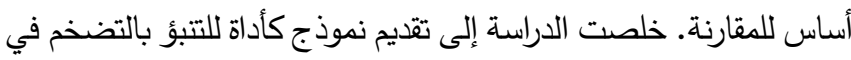
سعر الأسمنت وبالتالي في صناعة البناء والتشييد.

1.2 بيان مشكلة البحث وأهدافه: (Research Problem) الهدف هو تحديد ديناميات التضخم في قطاع البناء والتشييد في الاقتصاد السوداني باستخدام أسعار الأسمنت كمدخلات. على وجه التحديد الدراسة • تحديد الاتجاه التضخمي في قطاع البناء في الاقتصاد السوداني (الأسمنت نموجاً).

• تحديد السلوك التضخمي لبيانات أسعار الأسمنت مقابل معدلات التضخم الرسمية وغيرها من مقاييس التضخم الوطنية في السودان.

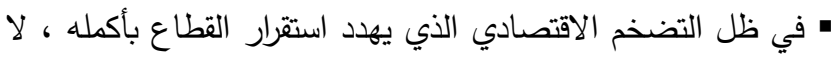
تحتوي الممارسة المهنية واللوائح السودانية على معاملة متطورة وفعالة لحماية قطاع البناء والتثييد والتكيف مع عصر العولمة والنهضة الاقتصادية التي تستند إلى هجرة رأس المال إلى البلدان

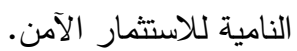
تتلخص أهداف هذا البحث في الآتي:

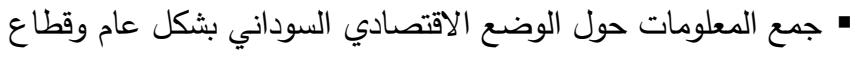

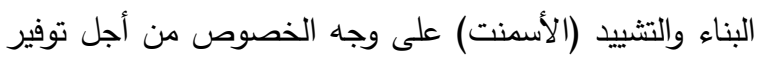
البيانات البحثية للمساعدة في دراسة وحل مشاكل صناعة البناء البناء

$$
\text { والتشييد وتطويرها. }
$$

• دراسة ومعرفة نمط وسلوك التغيرّ في قطاع البناء والتثييد (الأسمنت) مقارنة بالتغيُر في المؤشرات الاقتصادية التي تؤخذ في الاعتبار

$$
\text { في هذه الدراسة. }
$$

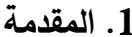

(PREFACE) : 1.1

استقرار الأسعار هو أحد أهم الأهداف الإقتصادية في أي اقتصاد، فلابد أن

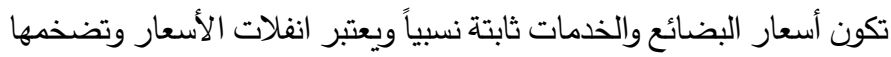

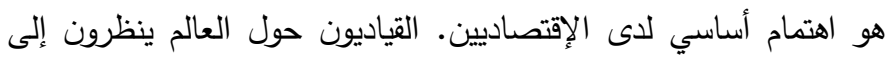
Begg التضخم على أنه ظاهرة إقتصادية يجب القلق حيالها. في تقرير الإنائ

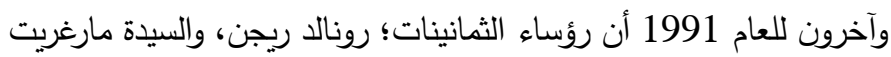
تاتشر ، والمستثار هيلموت كول، والكثير من قادة العالم الآخرين؛ أنهم قد العاك

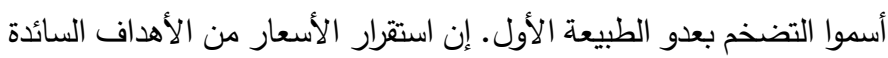

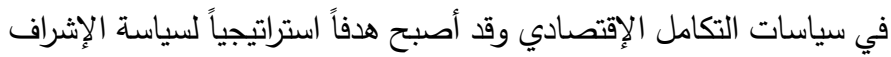
في أفريقيا والسودان. ضغط التضخم يعرف بتأثيره على مرافق المجتمع وأنه

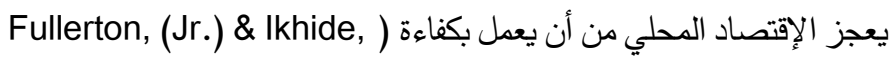

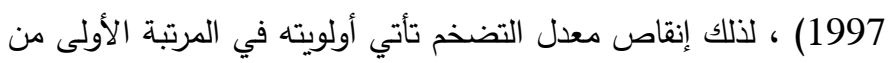
أجندة أي سياسة إقتصادية. أشار Palmer and Faseku (1982) إلى أن ثلاثة مؤشرات تستخدم

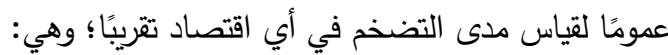

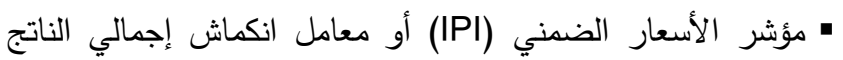

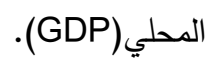
• مؤشر أسعار الجملة (WIPE). • مؤشر أسعار المستهلك (CPI).

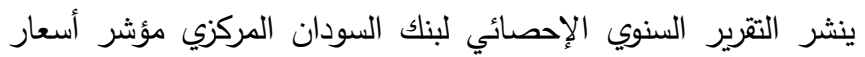

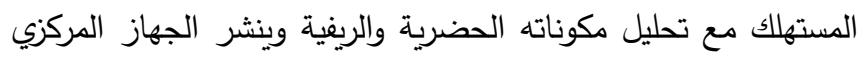
للإحصاء معدل التضخم والمعلومات الأخرى ذات الصلة.

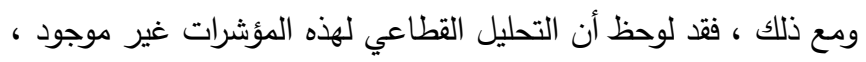

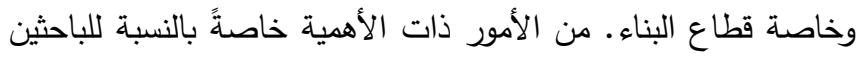
والممارسين الحوجة إلى تحديد الضغط التضخمي الكمي على صناعة التهاه

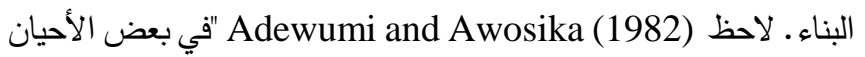
قد يكون التضخم مقصورًا على قطاعات معينة فقط من الاقتصاد أو قد يتواجد بكثافة متفاوتة في قطاعات مختلفة من الاقتصاد"، من خلال حقيقة أنه عندما يكون هناك ترابط قليل بين القطاعات ، فمن المككن أن تكون

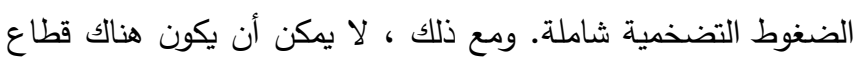

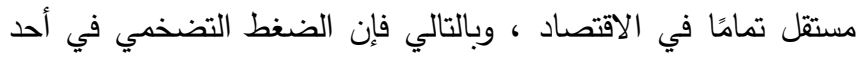

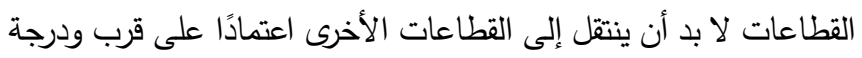

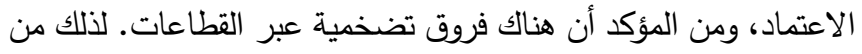
المرغوب فيه فهم هذا النمط التضخمي داخل القطاع ذي الأهية الخاصة. 
ولتغطية موضوع البحث، فإن الباحث إتبّع منهجية الإستقراء من واقع

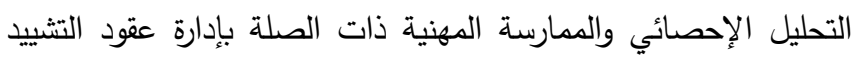

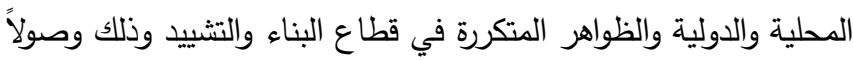

لتنسير منطقي لتلك الظواهر ليسهل التعامل معها في عقود التشييد. 2. الإطار النظري وإلدراسات السابقة Litreature Review and previos Studies

2.1 المؤشرات الإقتصادية: (Economic Indicators)

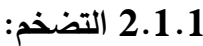

منذ الحرب العالمية الثانية ، شهدت معظم البلدان زيادات مستمرة وسريعة

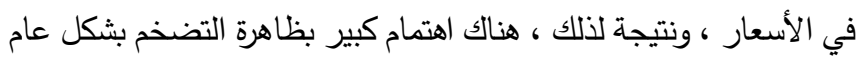

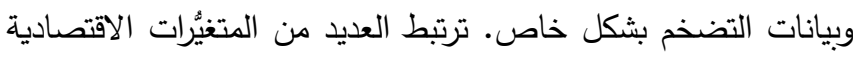

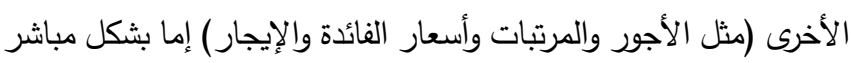

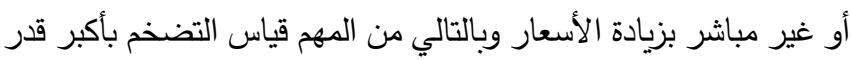

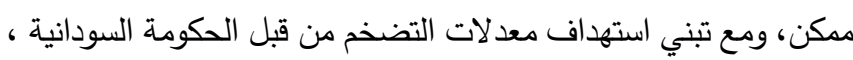
أصبح قياس التضخم أكثر أهمية.

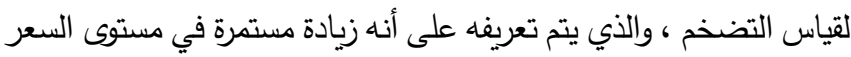
العام ، يجب تحديد معيار مستوى السعر العام وفترة مناسبة لقياس التغييرات

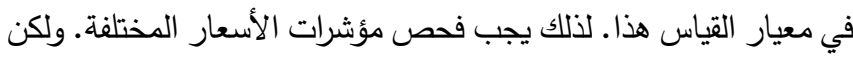

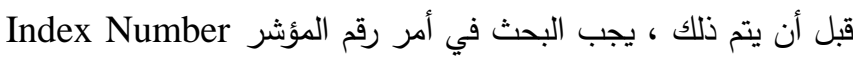

بصفة عامة.

Index Numbers : 2.1.2 أرقام المؤشرات

كما ذكر أعلاه ، يتم تعريف التضخم على أنه زيادة مستمرة في مستوى

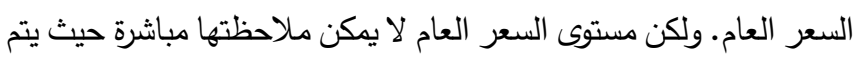
التعبير عن كميات السلع والخدمات في مجموعة متتوعة من الوحدات

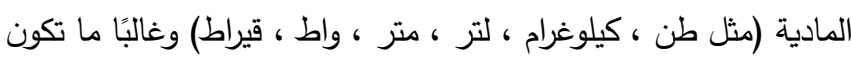

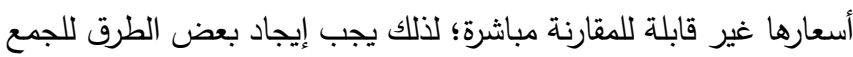
بين أسعار مجموعة واسعة من السلع والخدمات في رقم واحد. يتمثل الحل في استخدام أرقام المؤشر على نطاق واسع وفي هذا القسم نحصر أنفسنا في الجوانب المطلوبة لفهم تجميع وتفسير مؤشرات الأسعار Indices I العامة أو المركبة. يشير رقم المؤشر إلى مستوى وحدود متغيُر مركب واحد بالنسبة لمستواه في آلماني وقت آخر خلال فترة أخرى في مكان آخر ، وهلم جرا. أهم التغييرات

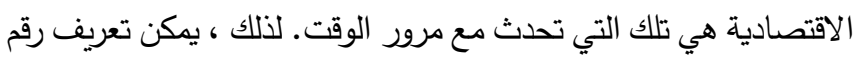

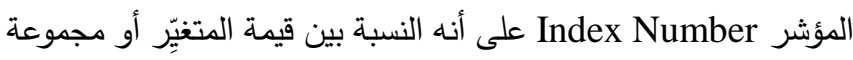

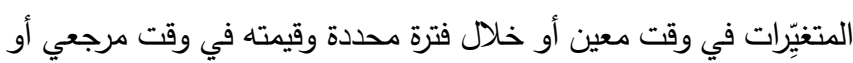

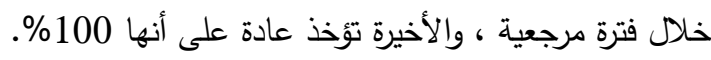

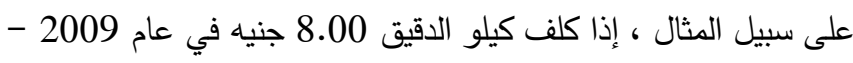

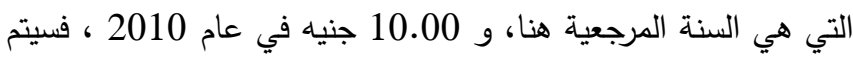
حساب رقم المؤشر لعام 2010 كما يلي: $\times 100=125 \frac{10,00 \text { SDG }}{8,00 \text { SDG }}$

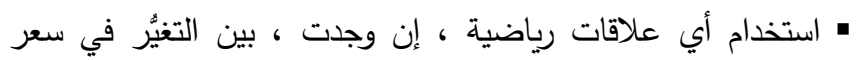

$$
\text { الأسمنت والمؤشرات الاقتصادية المدروسة. }
$$

- إمكانية استخدام العلاقات الرياضية المشتقة للحفاظ على استقرار عقود الاقدادئ النيناء.

1.3 أهية البحث: (Research Importance)

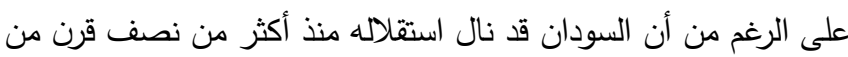
الزمان ، إلا أن قطاع البناء والتشييد في البلاد لم يأخذ شكله العام إلا في وقت قريب خلال العقدين الماضيين بعد التتقيب عن النفط وعلامات الاستقرار التي أعقبت توقيع اتفاق السلام. يجب أن يتزامن التحول الواضح

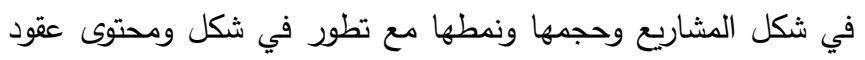
التشييد بطريقة تتماشى مع القوانين والأنظمة الجديدة في البلاد والقوانين

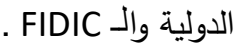

إن استقرار الأسعار هو أحد الأهداف الاقتصادية الرئيسية في أي اقتصاد، و من المرغوب فيه أن يظل مستوى السعر الإجمالي للسلع والخدمات ثابتًا.

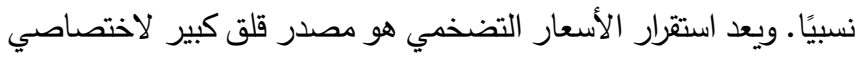
الإقتصاد كما يرى القادة في جميع أنحاء العالم أن التضخم ظاهرة اقتصادية

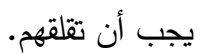
من المعروف أن عمليات البناء والتثييد والبنية التحتية تحتاج عادة إلى

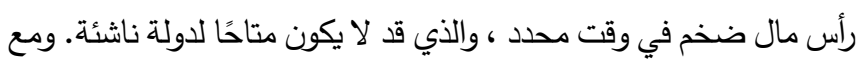

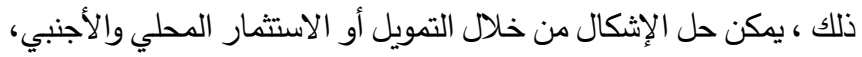
لكن الاستثمار الأجنبي يتأثر مباشرة باستقرار القوانين والتتظيمات الاقتصادية، وبسبب التضخم فإن مثل هذا النوع من القوانين يتغيرُ دائمًا

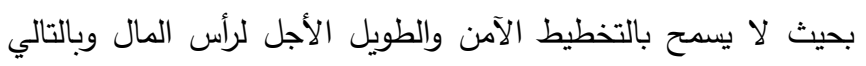
التخطيط للمشاريع التي تحتاج إلى رأس مال ضخم. وبالنسبة لهذه العوامل

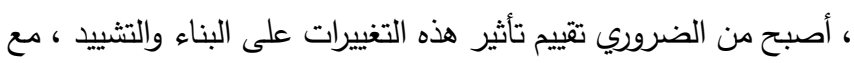
الأخذ في الاعتبار أن العقود ذات الصلة عادة ما تكون دولية وتشمل أطرافًا

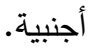

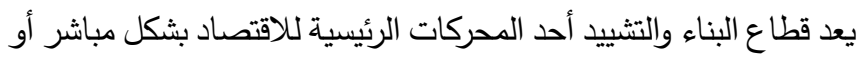
غير مباشر • ونظرًا للتضخم الاقتصادي ، فإن هناك نقص في آلية نقل التأثير القانوني والإقتصادي بشكل صارم إلى سوق البناء والتشييد ، وعليه يتجدد السؤال حول ما هو التأثير الفعلي (قصير أو طويل الأجل) لهذها لهانه التغييرات الناتجة عن التضخم على قطاع البناء والتشييد في السودان.

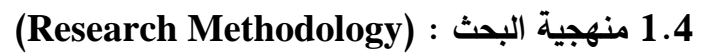
هذا البحث يختبر ظاهرة التضخم في السودان وتأثيرها على قطاع البناء والتشييد (الأسمنت نموذجاً). المنهجية المستخدمة هي مقارنة قيم التضخم وأسعار الصرف خلال الفترة المختارة مع أسعار الأسمنت في السودان لذات الفترة وذلك لتونئ لتوفير أساس

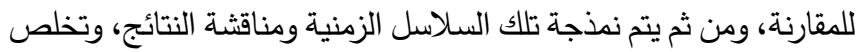
الدراسة في هذا الجانب إلى تقديم تلك النماذج كأدوات للتتبؤ بالتضخم في لتصني صناعة البناء والتشييد كنوع من أنواع إدارة المخاطر . 
2.2 الاراسات والحلول السابقة: Previous studies \&

Solutions

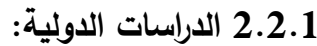

معظم الدراسات السابقة تتناول مشكلة البحث في التضخم في إطار قيمة المال مع مرور الوقت باستخدام سعر الفائدة وذلك لأن معظم هذه الاقتصاديات مستقرة ، وإذا كان هناك أي تضخم فإنه يكون لفترة قصيرة. كانت إحدى الدراسات القليلة التي أجريت في بريطانيا ، آخذة في الاعتبار معلومات تكلفة مواد البناء خلال الفترة (1978-1991) ، وأظهرت أن الزيادة في أسعار البناء خلال 15 سنة كانت 10 ٪ فقطوكانت خلال حرب

$$
\text { فوكلاند في عام } 1982 .
$$

في عام 2011 ، حاولت ورقة بحثية في جامعة كامبريدج حساب التغييرات

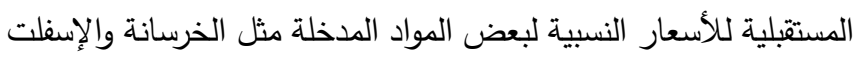

والصلب مع مراعاة التغئرات في أسعارها من خلال صيغها لبعاد العادية.

\begin{tabular}{|c|c|c|c|}
\hline الصلب & الأسفلت & الخرصانة & \\
\hline$-0.16 \%$ & $1.25 \%$ & $-0.17 \%$ & الأسعار النسبة المئوية السنوية للتنئر الحقيقي في \\
\hline
\end{tabular}

وإذا استخدمنا نتائجها ، فيمكننا أن نخفض أكثر من تكلفة البناء المعتادة وهي قيم تعكس استقراراً طويلاً في العملية الاقتصادية لبيانات الدراسة.

FIDIC 2.2.2 الاتحاد الدولي للمهندين الاستشاريين تتعامل FIDIC مع مشكلة التضخم من خلال معالجة تأثيراتها في عقود البناء، وليس بالتعامل مع المشكلة نفسها.

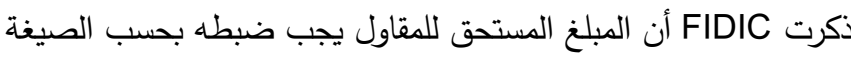

$$
\mathrm{P}=\mathrm{a}+\mathrm{b} \frac{L n}{L}+c \frac{E n}{E}+d \frac{M n}{M}+\ldots
$$

Pn a : معامل ثابت يمثل الجزء غير القابل للتعديل في الدفع التعاقدي

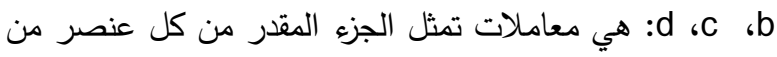
عناصر التكلفة المتعلقة بتتفيذ الأعمال. Ln و En و Mn و ... و L و E و و M و ... تمثل مؤشرات التكلفة الحالية والأساسية أو الأسعار المرجعية.

2 2.2.3 صيغة وزارة المالية:

حاولت وزارة المالية الإتحادية في السودان التعامل مع تأثير التضخم في قطاع البناء في السودان وقامت بصياغة معادلة تبدو متشابهة مع صيغة الإنة FIDIC

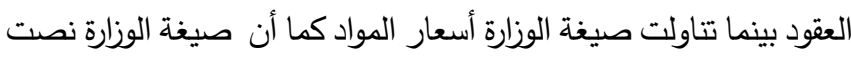

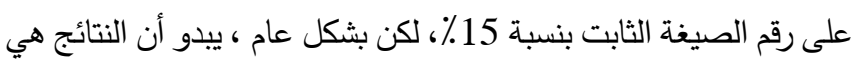

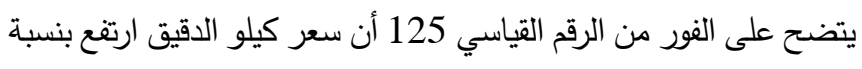
25 ٪ من عام 2009 (فترة الأساس) إلى 2010. وبالمثل ، إذا كان عام إن المان 2009 هو فترة الأساس لمؤشر والرقم القياسي لعام 2011 هو 135 من الواضح على الفور أن قيمة المتغيُر أو مجموعة المتغيُرات المعنية زادت لئري بنسبة 35٪ بين عامي 2009 و 2011. المؤشر عبارة عن سلسلة من أرقام المؤشر بتردد ثابت (على سبيل المثال ، شهر ، ربع سنة ، سنة). يحتوي مؤشر معين ، مثل مؤشر إنتاج الذرة ،

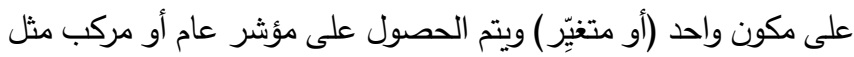

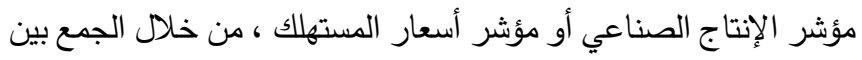
متغيِرات مختلفة أو مؤشرات محددة في مؤشر واحد. يتضمن إنشاء مؤشر عام أو مركب خمس خطوات أساسية: • اختيار العناصر أو المكونات (السلة أو النظام)

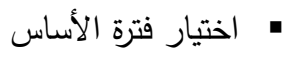

• عيين الوزن للعناصر أو المكونات المختلفة.

$$
\begin{aligned}
& \text { • جمع البيانات } \\
& \text { • حساب أرقام المؤشر }
\end{aligned}
$$

\subsection{3 حساب معدل التضخم: Calculating Inflation Rate} يفضل أن يكون معدل التضخم دائمًا سنويًا ، أي معبرًا عنه بمعدل سنوي. وفي الواقع ، نظرًا لأن التضخم عبارة عن عملية زيادات مستمرة في الأسعار

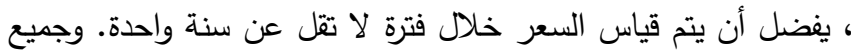
الأسعار المدرجة في مؤشر أسعار المستهلك ومؤشرات الأسعار الأخرى لا لا لأل

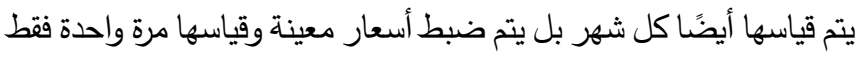

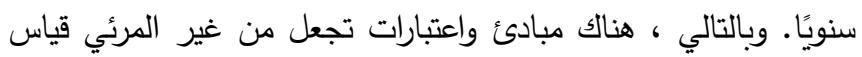
التضخم على مدى فترات قصيرة جدًا (مثل شهريًا). في الممارسة العملية ، يظهر اهتمام كبير بأحدث مؤشرات الأسعار الشهرية

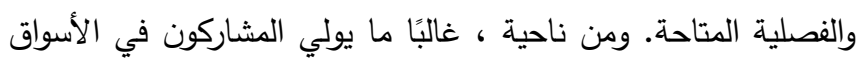

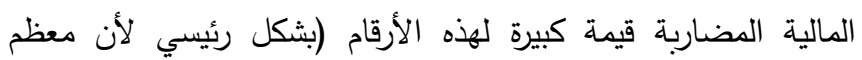

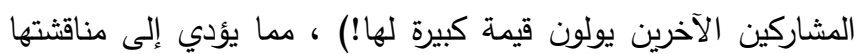

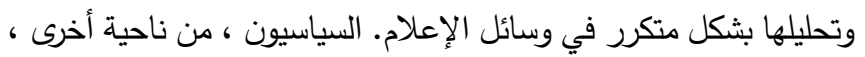
يبحثون عن أرقام يمكنهم من خلالها تكوين رأس مال سياسي حيث الإسلائل يحتاج

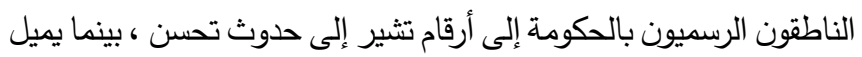

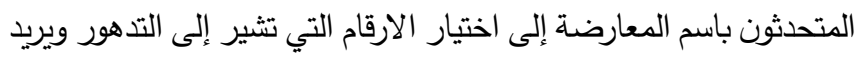

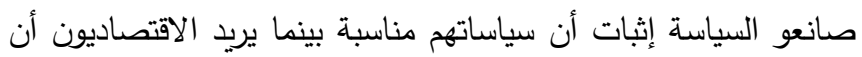

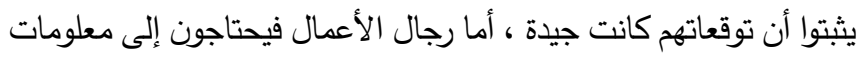
حول الاتجاه الأخير لأغراض التخطيط.

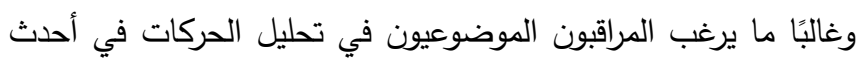

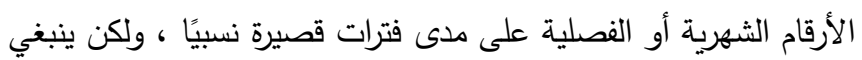
القيام بذلك فقط مع إيلاء الاعتبار الواجب للاتجاه الأساسي على مدى الإى

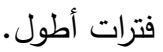


2. صعوبة قياس بعض المتغِِرات المستقلة ، مثل قياس المتغِِرات في

الدراسات النفسية.

3. عدم وصف نموذج الانحدار بدقة.

4. هنالك أخطاء في قياس المتغيِرات التابعة والمتغِِِرات المستقلة. 5. وجود عنصر عشوائي في السلوك البشري وإدراج متغِِّر في المتغِّرِ

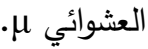

3. جمع البيانات وتحليلها: Data Collection and Analysis

Data Collection: 3.1

انقسمت المعلومات والبيانات المطلوبة لإنجاز هذا البحث إلى فرعين

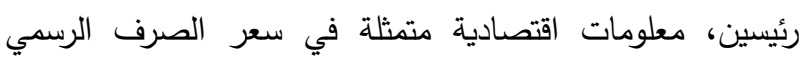
والموازي لسنوات البحث بالإضافة لمعدل التضخم، ومعلومات تراكمية

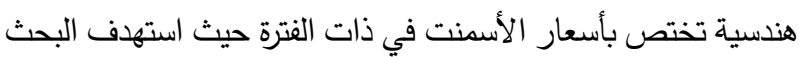
جمع البيانات للفترة من العام 2000م وحتى 2016م. كانت هنالك سهولة نسبية في الحصول على بيانات التضخم من من مصادرها الرسمية متمثلة في بنك السودان المركزي ووزارة المالية الاتحادية وفق منشورات إحصائية، ولم تكن هناك أي بيانات رسمية تختص بسعر الصرف الموازي للدولار مقابل الجنية السوداني حيث تم

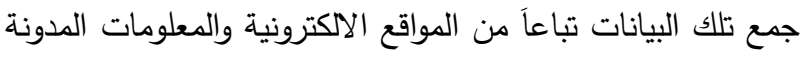
لاى الباحث والصحف اليومية وبعض المتعاملين الثقاة في ذلك المجال

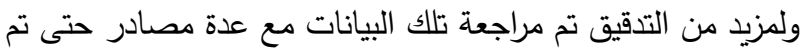
الاطمئنان لدقتها وتمثيلها الحقيقي للفترات المأخوذة فيها.

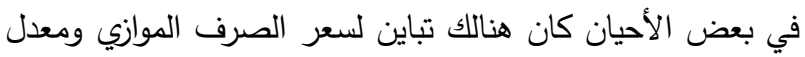
التضخم خلال العام الواحد وتم التظلب على ذلك الأمر بتطبيق المتوسط الحسابي للعام الدحدد وفق بيانات الارباع الأربعة فيه. واجهت الباحث صعوبات بالغة في الحصول على البيانات الخاصة بأسعار الأسمنت، حيث لم تكن أي من الجهات الرسمية في البلاد لديها

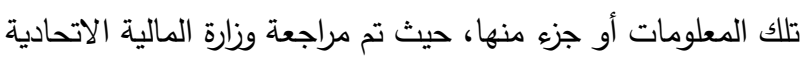
ووزارة المالية بولاية الخرطوم ووزارة التخطيط العمراني ووزارة البنى لانى التحتية بولاية الخرطوم والهيئة العامة للطرق والجسور والجهاز المركزي للإحصاء ودار الوثائق القومية ومراكز البحوث والمكتبات الجامعية، مما أضطر الباحث في نهاية الامر لتجميع تلك البيانات

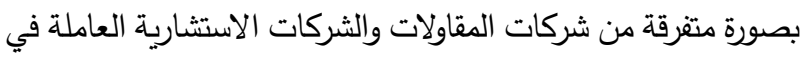
السودان، بالإضافة للبيانات الإحصائية لشركات مصانع الاسمنت وشركات توريد وبيع مواد البناء.

بعد جمع تلك المعلومات تم فرزها ومراجعتها بالاعتماد على خبرة

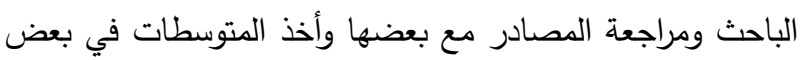
الأحيان بين البيانات المتوفرة إلى أن تم الوصول إلى قائمة بيانات تمثل

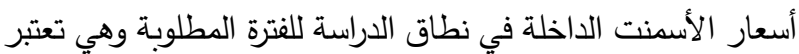

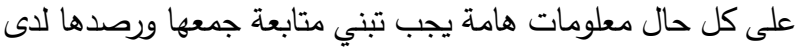
واحدة من الجهات المختصة لأغراض البحث والإصلاح.
2.3 مفهوم طربقة المربعات الصغرى:

يمثل تحليل نموذج الانحدار طبيعة العلاقة بين المتغيرات الاقتصادية وافتراض وجود علاقة خطية بسيطة بين المتغير التابع (Y) والمتغير لئي المستقل (X) الذي تمثله العلاقة التالية: $(1-3) Y=f(x)$

ويمكن أن تكون العلاقة خطية أو غير خطية. وتكمن معرفة خطية العلاقة

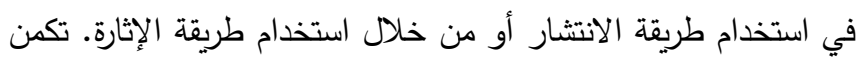
طبيعة طريقة الانتشار في حقيقة أن الباحث يجمع البيانات حول المتغيرات المختلفة في النموذج ثم يراقب هذه البيانات في شكل انتشار ثنائي المحور يتضمن المتغير التابع على محور واحد والمتغير المستقل على المحور الآخر. من خلال فحص شكل الانتشار ، يمكن للباحث اختيار الشكل

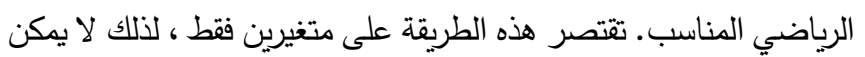
استخدام هذه الطريقة في حالة انحدار تحتوي على أكثر من متغيرين. يوضح الثكل التالي (2-2) طريقة انتشار المتغيرّات (X X (Y):

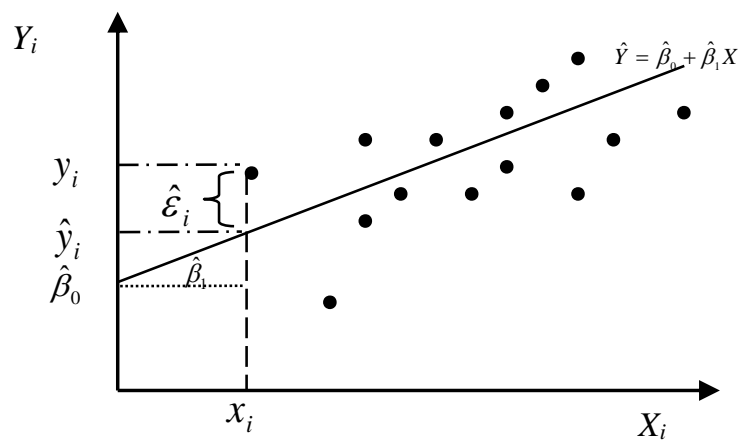

$$
Y_{i}=\hat{\beta}_{0}+\hat{\beta}_{1} * X_{\mathrm{i}} \quad-----(2-3)
$$

حيث:

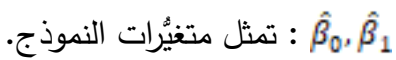
غالبًا ما يتم إعطاء النظرية الاقتصادية بشكل محدد ، فئرات الني في حين أن العلاقة المتضمنة في النظرية تخضع لككون عشوائي. لغرض القياس الإحصائي ، يجب إضافة متغيُر عشوائي فيما يتعلق بعدم وجود علاقات كاملة في القياس. العلاقة المطلقة هي أن المتغيُرات المدرجة في الدراسة تفسر 100

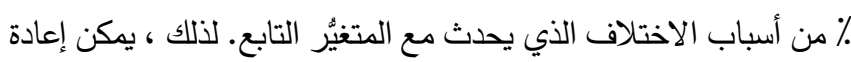
كتابة المعادلتين (1-3) و (2-3) على النحو التالي:

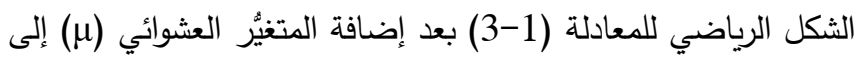

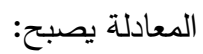

$$
Y=f(X)+\mu----(3-3)
$$

الصيغة القياسية للمعادلة (2-3) بعد إضافة المتغيُر العشوائي ( ب لر)

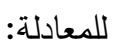

$$
\begin{aligned}
& Y=\beta_{0}+\beta_{1} * X_{\mathrm{i}}+\mu_{\mathrm{i}}-----(4-3) \\
& \text { إضافة المتغِيرِ العشوائي تُعلَّل بـ: }
\end{aligned}
$$

1. صعوبة إدخال جميع المتغِيّرات المستقلة التي تسهم في تغيير تباين المتغيّر Y بسبب عدم معرفة بعض المتغيّرات. 


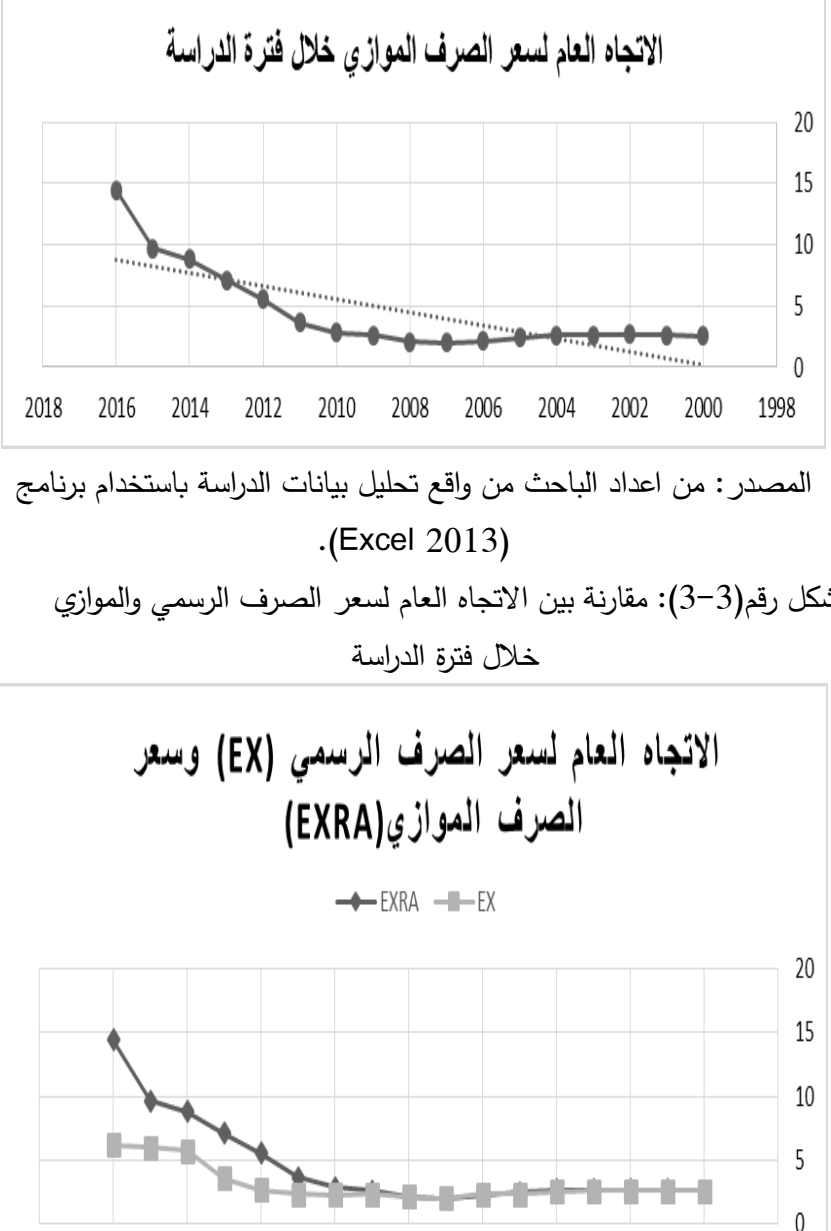

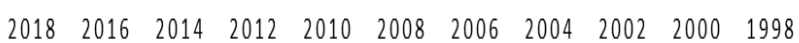

المصدر : من اعداد الباحث من واقع تحليل بيانات الدراسة باستخدام برنامج

.(Excel 2013)

جدول رقم (2-3): نتائج التقدير للنموذج

\begin{tabular}{|c|c|c|c|c|}
\hline المعنوية الكلية & معنوية المعالم & قيمة (t) & المعالم المقدرة & المتغيُرات \\
\hline Prob. Of $\mathrm{F}$ & Prob. Of $\mathrm{T}$ & T Statistic & Coefficient & Variables \\
\hline \multirow[t]{3}{*}{0.000000} & 0.0000 & 23.24869 & 4.521322 & C \\
\hline & 0.0225 & 2.565065 & 0.352995 & LOG(EXRA) \\
\hline & 0.0008 & 0.252157 & 0.523184 & LOG(INF) \\
\hline
\end{tabular}

المصدر :من اعداد الباحث من واقع تحليل نموذج الدراسة باستخدام برنامج

(Eviews V.9)

$\operatorname{LOG}($ CEMENT $)=4.52+0.35 * \operatorname{LOG}($ EXRA $)+0.52 *$ LOG(INF)

Test on Model Results الإختبارات على النماذج 3.2.3 للوصول إلى نموذج معادلة يصف واقع البيانات، فقد تم تنفيذ عدد من

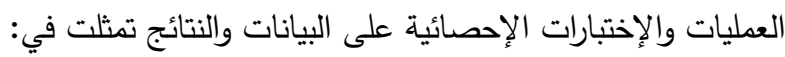
(i) (إختبار التكامل المشترك. (i) إختبار إستقرار متغيرات الدراسة. (ii) (iii)

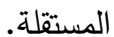

تقييم نتائج تقدير النموذج وفق المعيار الإقتصادي والإحصائي والقياسي.

\begin{tabular}{|c|c|c|c|c|}
\hline \multicolumn{5}{|c|}{ جدول رقم (2-3): البيانات الخام للدراسة } \\
\hline التضخم & سعر الصرف الموازي & الرسني الصري مقابل & سعر الأسمنت & 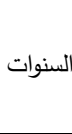 \\
\hline 8.02 & 2.585 & 2.57 & 340.00 & 2000 \\
\hline 4.92 & 2.65 & 2.61 & 340.00 & 2001 \\
\hline 8.3 & 2.68 & 2.61 & 340.00 & 2002 \\
\hline 7.7 & 2.64 & 2.6 & 340.00 & 2003 \\
\hline 8.46 & 2.625 & 2.51 & 340.00 & 2004 \\
\hline 8.5 & 2.435 & 2.31 & 340.00 & 2005 \\
\hline 7.2 & 2.171 & 2.31 & 340.00 & 2006 \\
\hline 8.1 & 2.015 & 2.01 & 410.00 & 2007 \\
\hline 14.3 & 2.057 & 2.1 & 410.00 & 2008 \\
\hline 11.2 & 2.604 & 2.33 & 485.00 & 2009 \\
\hline 13 & 2.823 & 2.28 & 650.00 & 2010 \\
\hline 18.5 & 3.627 & 2.32 & 1000.00 & 2011 \\
\hline 35.1 & 5.535 & 2.66 & 980.00 & 2012 \\
\hline 35 & 7.107 & 3.56 & 1100.00 & 2013 \\
\hline 37.1 & 8.807 & 5.71 & 1200.00 & 2014 \\
\hline 37 & 9.681 & 6.01 & 1350.00 & 2015 \\
\hline 30.47 & 14.455 & 6.22 & 1500.00 & 2016 \\
\hline
\end{tabular}

3.2 نموذج تقدير أثر التضخم وسعر الصرف الموازي على اسعار الاسمنت: - الاست

The model of Inflation and parallel exchange rateeffect on the price of cement:

Presenting : 3.2.1 توضيح الاتجاهات العامة لمتغئرات النموذج: of the general trends of the model variables: شكل رقم (1-3): الاتجاه العام للمتغيرُ التابع (سعر الاسمنت) خلال فترة الدراسة

\section{الاتجاه العام لسعر الأسنت خلال فترة الاراسة}

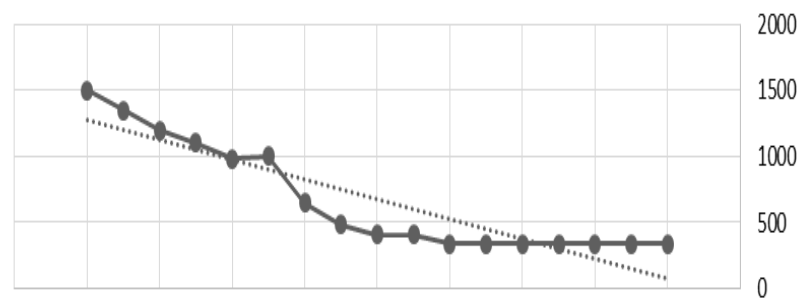

$\begin{array}{lllllllllll}2018 & 2016 & 2014 & 2012 & 2010 & 2008 & 2006 & 2004 & 2002 & 2000 & 1998\end{array}$

المصدر : من اعداد الباحث من واقع تحليل بيانات الدراسة باستخدام برنامج

(Excel 2013)

شكل رقم (2-3): الاتجاه العام لسعر الصرف الموازي خلا فترة الدراسة

The model estimation results: 3.2.2 نتائج تقدير النموذج بالاعتماد على أسلوب التجريب توصل الباحث إلى أن الثكل الرياضي الأمثل لتقدير نموذج الدراسة هي الدالة اللوغاريثية الكاملة

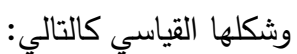
$\operatorname{LOG}\left(\right.$ CEMENT) $=\beta_{0}+\beta_{1} * \operatorname{LOG}($ EXRA $)+\beta_{2} * \operatorname{LOG}(\mathrm{INF})+\mu$ 
الخرسانة الجاهزة تضاعفت ست مرات تقريباً حيث كان المتر المكعب في

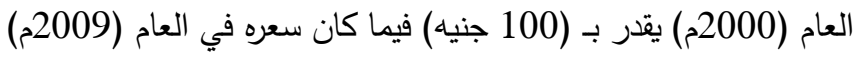
قد بلغ (460 جنيه) وفي العام (2010م) بلغ (610 جنيه) مما يشير إلى لئى

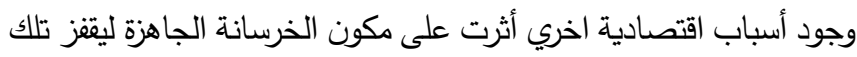

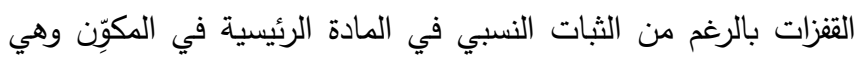

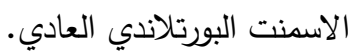
- بصورة عامة يلاحظ ثبات المؤشرات الاقتصادية التي اعتمدتها الدراسة

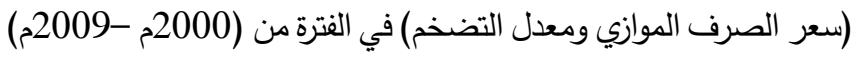

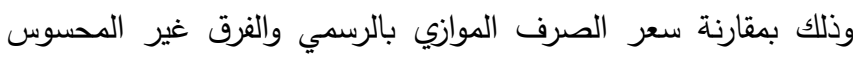

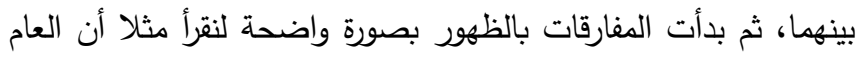
(2014م) سجل سعر الصرف الرسمي (6.01 جنيه) مقابل الدولار الأمريكي في حين كان السعر الموازي هو (14.455 جنيه) وهو فرق كبير الرسير

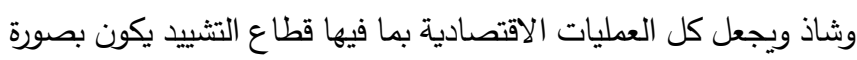
كبيرة غير مقروءاً مع السعر الرسمي والذي هو أقرب إلى أن يكون سعراً

\section{داخلياً لمعاملات الدولة الرسمية.}

\section{3}

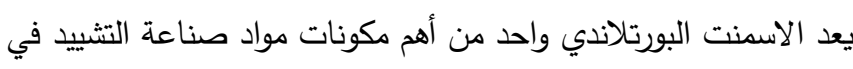

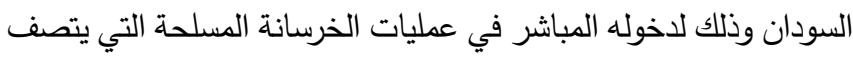
بها معظم بناء السودان القطر بالإضافة لاخوله كمكون في معظم عمليات

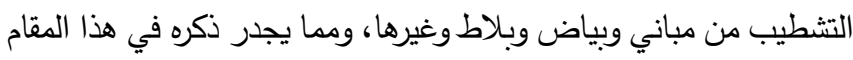

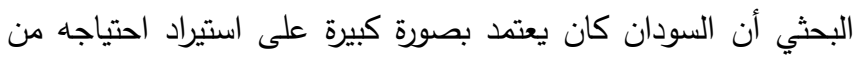

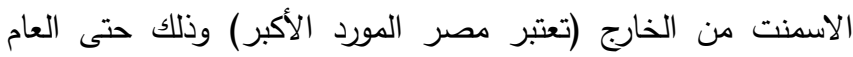

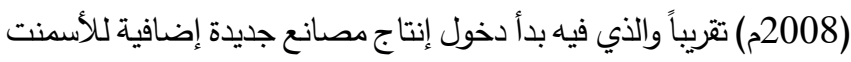
في السودان إضافة إلى المصنعين القديمين (مصنع عطبرة ومصنع ربك)

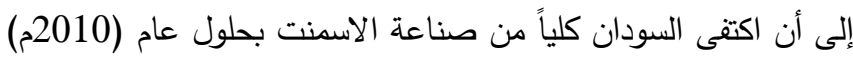
تقريباً وصار الاستهلاك المحلي الحقيقي المستتفذ أقل من الطاقة التشغيلية

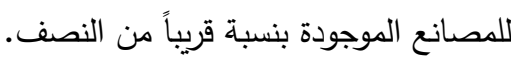

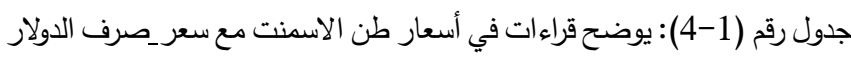

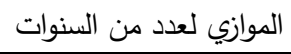

\begin{tabular}{|c|c|c|c|}
\hline بالدولار الأمريكي وفق الاسمنت & الاسمنت إلى العام طن & الدولار الموازي إلى صرف & العام \\
\hline 156.6 & & & 2006 \\
\hline 203 & & & 2007 \\
\hline 157 & & & 2008 \\
\hline 171 & & & 2009 \\
\hline 179 & 1.34 & 1.28 & 2010 \\
\hline 180 & 1.54 & 1.53 & 2011 \\
\hline 140 & 1 & 1.28 & 2012 \\
\hline 125 & 1.1 & 1.24 & 2013 \\
\hline 123 & 1.1 & 1.1 & 2014 \\
\hline 93 & 1.13 & 1.49 & 2015 \\
\hline 93.8 & 1.11 & 1.11 & 2016 \\
\hline
\end{tabular}

Results and Discussion 3.2.4 عرض ومناقشة النتائج 4.1 مقدمة: Introduction

السودان بلد استثنائي في شكل الاقتصاد الذي يعيشه وفق دلائل المؤشرات الاقتصادية المرصودة مثل معدل التضخم و سعر الصرف للعملات الحرة

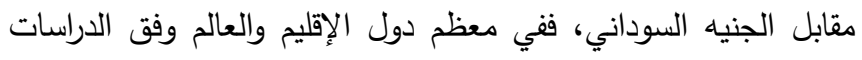

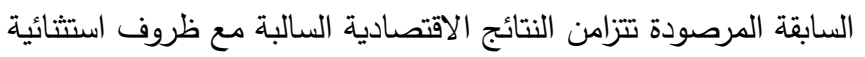

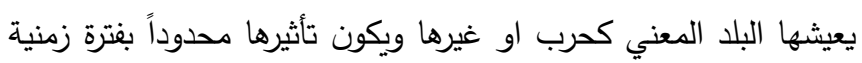

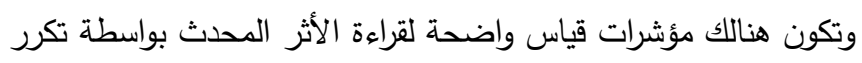
التغيرّات السالبة، ثم لا يلبث أن يعود الوضع إلى الاستقرار مجدداً - سالباً

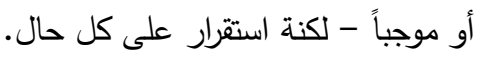
وفق البيانات المرصودة فان الاقتصاد السوداني عاش فال فترة عدم استقرار في أسعار صرف العملات الأجنبية مقابل الجنيه السوداني كواحدة من آثار الإد

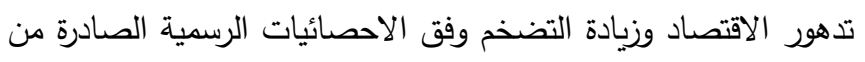

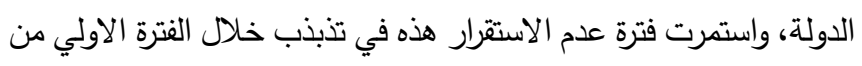

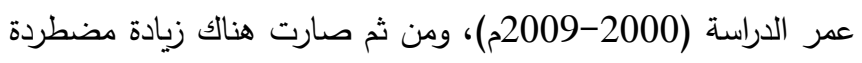

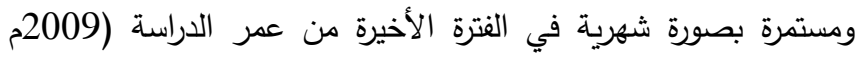

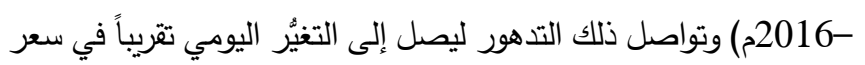
صرف العملات مقابل الجنيه السوداني. واحدة من النتائج المهمة لهذه الدراسة أنها المرة الأولي تقريباً التي يتم فيها

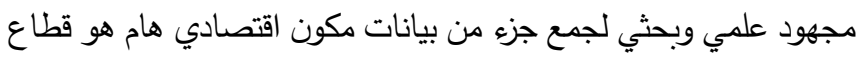

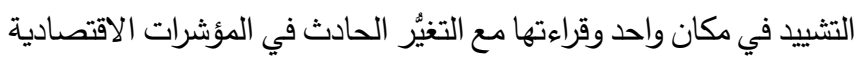
المؤثرة عليها كمعدل التضخم وسعر صرف الدولار الموازي مقابل الجنيه

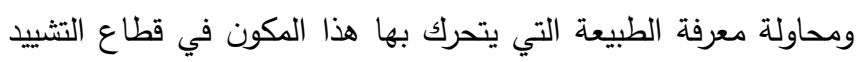
وعلاقته بالمؤشرات الاقتصادية المدروسة، ويمكن تلخيص النتائج التي تم تم

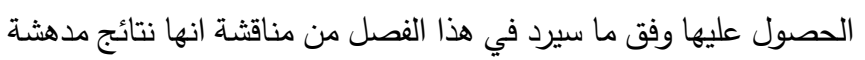
تفتح بابا جديداً من أبواب البحوث الهندسية المختصة بهندسة القيمة والتي لهني

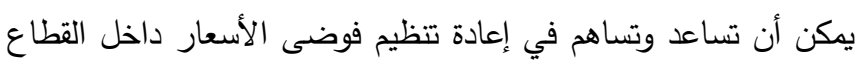

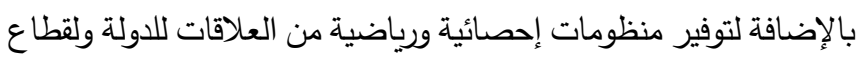
الاعمال بصورة عامة من مقاولين واستشاريين ومديري مشروعات،

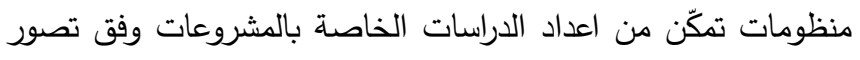
حقيقي للواقع وقراءة معقولة للمستقبل وما يحمله من مخاطر . 4.2 قراءة عامة: أن وضع البيانات المجرد لأسعار الأسمنت مع سعر الصرف الموازي

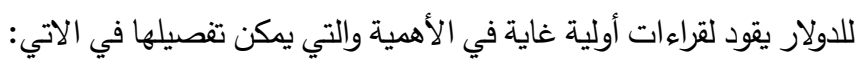
- شهدت الفترة الزمنية من العام (2000م) وحتى (2009م) استقراراً معقولاً في سعر صرف الدولار الأمريكي مقابل الجنيه السوداني وكذلك في التي معدل التضخم مما يوجه قراءة أي فجوات في أسعار الأسمنت لعوامل اخري الأليك

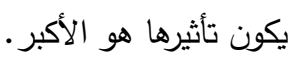
- بالرغم من الاستقرار المذكور في الوضع الاقتصادي العادي العام للفترة الاولي

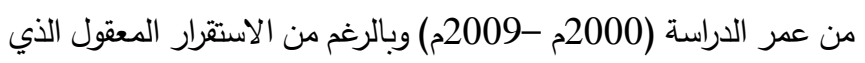

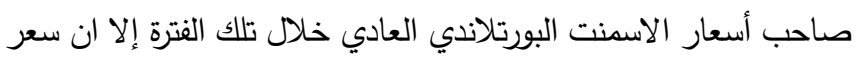




\section{5. الخلاصة والتوصيات Conclusion and Recomondations}

5.1 الخلاصة: Conclusion

تم استتباط معادلة تفسر وتوضح العلاقة بين سعر الأسمنت مع كلاً من

سعر الصرف الموازي ومعدل التضخم، ملخصها كالاتي: جدول رقم (1-5): ملخص المعادلات المقدرة باستخدام سعر الصرف الموازي ومعدل التضخم

\begin{tabular}{|c|c|c|c|}
\hline 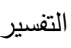 & المعادلة المقدرة & 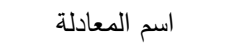 & بند \\
\hline \multirow[t]{3}{*}{$\% 90$} & LOG(CE(ME) & معادلة تغيُر سعر طن & .1 \\
\hline & $N T)=4.76+0.35 * \mathrm{LOG}(\mathrm{EXRA}$ & الأسمنت مع التضخم & \\
\hline & )+0.52* LOG(INF) & وسعر الصرف & \\
\hline
\end{tabular}

المصدر :من اعداد الباحث من واقع تحليل نموذج الدراسة باستخدام برنامج (Eviews V.9)

جدول رقم (2-5) يبين مقارنة بين القيم التتبؤية وفق المعادلات المستتبطة والقيم الفعلية المرصودة لفترة البحث (2000-2016)

\begin{tabular}{|c|c|c|}
\hline التتبؤي بالمعادلة المستتبطة الأسمنت & سعر الأسمنت & السنوات \\
\hline 416.05 & 340.00 & 2000 \\
\hline 340.45 & 340.00 & 2001 \\
\hline 428.33 & 340.00 & 2002 \\
\hline 412.25 & 340.00 & 2003 \\
\hline 428.33 & 340.00 & 2004 \\
\hline 416.60 & 340.00 & 2005 \\
\hline 370.61 & 340.00 & 2006 \\
\hline 378.53 & 410.00 & 2007 \\
\hline 487.46 & 410.00 & 2008 \\
\hline 481.79 & 485.00 & 2009 \\
\hline 530.47 & 650.00 & 2010 \\
\hline 681.95 & 1000.00 & 2011 \\
\hline 1062.50 & 980.00 & 2012 \\
\hline 1171.75 & 1100.00 & 2013 \\
\hline 1308.18 & 1200.00 & 2014 \\
\hline 1356.58 & 1350.00 & 2015 \\
\hline 1462.79 & 1500.00 & 2016 \\
\hline
\end{tabular}

قام الباحث بمحاولة لاستقراء سعر الأسمنت وفق المعادلات للسنوات 2017، 2018، 2019 والتي هي خارج نطاق الدراسة ومن ثم مقارنتها مع القيم الحقيقية لذات السنوات كما هو مبين في الجدول رقم (3-5). وقد وجد الباحث تبايناً كبيراً في أسعار طن الأسمنت يفوق نسب الخطأ

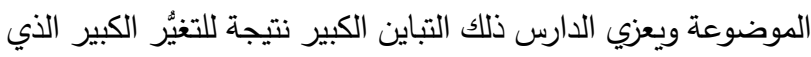
حدث في سعر الصرف في العام 2017 مما جعل هناك قفزة كبيرة في الأسعار، بالإضافة للتغيُر الكبير الذي طرأ على السياسات الإقتصادية لذات الفترة من تغيير لسعر صرف الدولار الجمركي ضريبياً حتى ثلاثة أضعاف، وذلك الأمر يتطلب دراسات إضافية لهذه الفترة وإلحاقها بالنتائج المستخلصة للسنوات التي قبلها.
المصدر : من إعداد الباحث بناءً على تحليل بيانات الدراسة.

بالرجوع إلى الجدول رقم (1-4) أعلاه والدستبط من البيانات الرئيسية المجموعة بواسطة الباحث نلاحظ أن الزيادات بصورة عامة في سعر إلمرات الاسمنت تتوافق مع الزيادات في السعر الموازي للدولار بنسب متماتلة تقريباً وذلك للفترة (2010م -2016م)، وإذا ما أخذنا في الاعتبار أن الزيادات في سعر الصرف الموازي حتى العام (2016م) كانت فصلية وبطيئة ثم صارت بعد ذلك شبة يومية وسريعة ومفاجئة وقرأنا ذلك مع سعر الدوات الدار الموازي في تاريخ إعداد البحث ونسبته إلى السعر في العام (2016م) نجده يمثل (3.9مرة)، وبالمثل عند قراءة النسبة في الزيادة في سعر الطن بين سعر اليوم والسعر في (2016م) نجدها (6.7 مرة) وهذا يدلل بوضوح إلى فئ أن الانفراط في عقد سعر الصرف الموازي أدي مباشرة إلى اختلال ميزان التسعير في سعر طن الاسمنت ليتضاعف السعر ستة مرات بدلاً عن ثلاثة مرات وفق المعدل المرصود في الجدول. بالرجوع إلى الجدول رقم (1-4) أعلاه ومشاهدة سعر طن الاسمنت

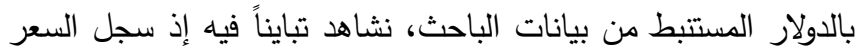

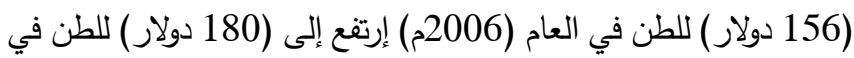

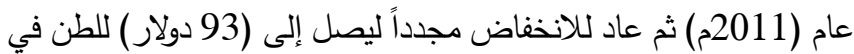
الأعوام (2015م) و (2016م) وبذلك يكون المتوسط العام لسعر طن الاسمنت بالدولار هو (108 دولار).

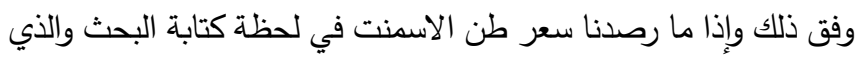
كان (10,000 جنيهاً) سودانياً ونسبناه إلى السعر الموازي للدولار في ذات اللحظة (63 جنيهاً) للدولار نجد أن سعر الطن لحظة كتابة البحث

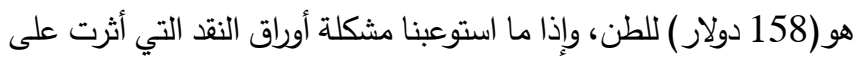

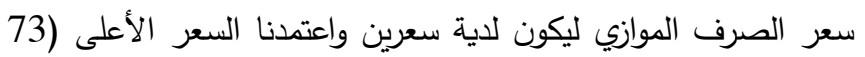

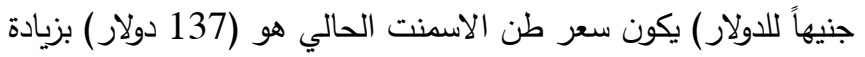
(29 دولار) عن المتوسط العام، ووفق ذلك تكون الخلاصات الآتية من

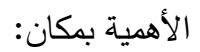
جدول رقم (2-4): خلاصة سعر الأسمنت

\begin{tabular}{|c|c|}
\hline 10,000جنيهاً & سعر طن الاسمنت لحظة كتابة البحث بالجنيه السوداني في السوق \\
\hline 6,789 جنيهاً & 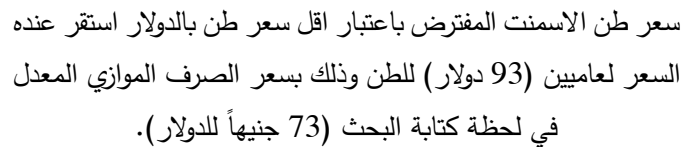 \\
\hline 7,884 جنيهاً & 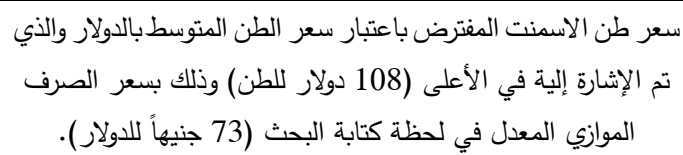 \\
\hline 2,664 جنيهاً & الزيادة المتوسطة في سعر الطن الحالي بالجنيه من السعر الدفترض أن \\
\hline$\% 34$ & نسبة الزيادة \\
\hline
\end{tabular}

الهصدر : من إعداد الباحث بناءً على تحليل بيانات الدراسة. 
2. إحداث تعديلات أساسية وإلزامية في عقود التشييد بالسودان الموقعة بالجنيه السوداني وذلك لتحتوي على بنود تعالج أثر تغيُر الأسعار

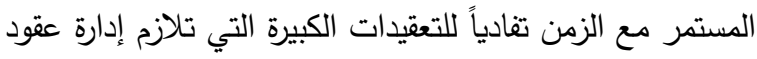

$$
\text { التشييد في السودان. }
$$

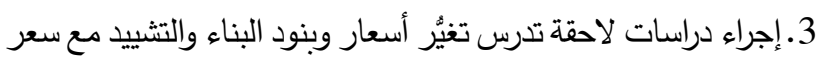
الصرف فقط بدون معدل التضخم وذلك لتأثر التغيُر في معدل التضخم ببعض القيود الرسمية التي قد لا تظهر القيم الحقيقية له ويتوقع أن تعطي تلك الاستتباطات نتائجاً أكثر دقة. 4. اجراء دراسات لاحقة تدرس علاقة التغيُر في سعر مواد وبنود التثييد

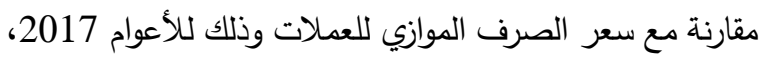
2018، 2019 والأعوام اللاحقة وإجراء التعديلات أو الإضافات

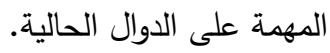

5. إنشاء مركز متخصص بالدراسات الإقتصادية ذات الصلة بقطاع

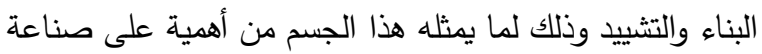

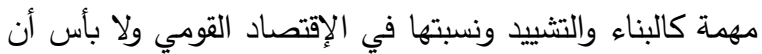
يكون ذلك الجسم تحت مظلة واحدة من المؤسسات الحالية كمجلس ولاس تنظيم مقاولي الأعمال الهندسية مثلاً.

\section{المراجع: References}

1. ohn A. White, Marvin H. Agee and Kenneth E. Case. Principles of Engineering Economic Analysis, third Edition. John Wiley \& Sons.

2. Philip Mohr (2003). Economic Indicators, Fourth Edition (2014). Van Schaik Publishers, 1059 Francis Baard Street, Hatfield, Pretoria.

3. Adejugbe, M. O. A. (1982). The Mechanisms and Dynamics of inflation in Nigeria - 1961- 1972. In H. M. A. Onitiri and K. Awosika (ed), Inflation in Nigeria NISER Ibadan: pp. 46-70.

4. Begg, D.; Fisher, S.; Dornbusch, R. (1991). Economics, third Edition McGraw-Hill Book Company, London.

5. Fullerton (Jr.). T. M... and Ikhide, S. I (1997). Inflationary Dynamics in Nigeria: Nigerian Journal of Economic and Social Studies. 39 (2), 205-219.

6. www.reading.ac.uk/centuar. The $\mathrm{PhD}$ in Construction Management, Conference or Workshop Item. Published by Salford, Association of Researchers in Construction Management.

7. M.B Taha. (2020). Modelling inflation Dynamics in the contraction Sector of adevelopng Economy and it's impact on infrastructure contracts.

Unpublished Ph.D thesis, Karari University. 8. بنك السودان المركزي - التقرير السنوي الرابع والخمسون 2014م.

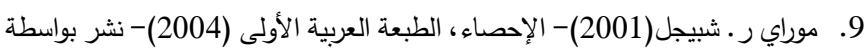

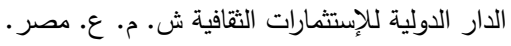

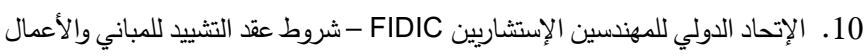
الهندسية المصممة بمعرفة رب العمل، إرشادات لإعداد الثروط الخاصة، نماذج الإنجان

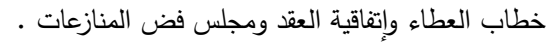

5.3 مقارنة المعادلات المستنبطة مع معادلتي الفيديك (FIDIC) و وزارة المالية الاتحادية بالسودان • • ملا معادلتي الفيديك (FIDIC) و وزارة المالية الاتحادية تقدم حلاً وقتياً للأثر الذي أحدثة التغيُر في سعر الصرف ومعدل التضخم على أسعار

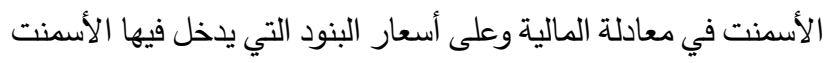

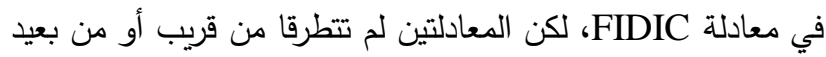
لشكل العلاقة الزمنية.

• كلا المعادلتين تقدمان حلاً معقولاً في حال الحدوث النادر لمشكلة خلال

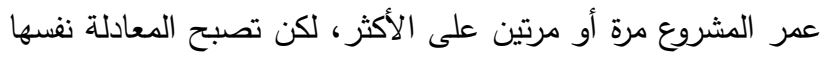

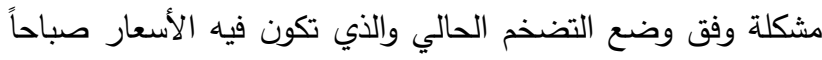
تختلف عن الأسعار في ذات اليوم مساءً وتصبح عملية الإحصاء

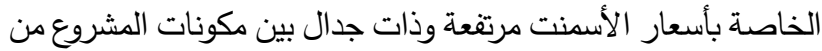
استشاري ومقاول ومالك وذلك للتباين الواضح في سعر تلك المادة وفق

$$
\text { وضع عدم الاستقرار • }
$$

•. المعادلات الحالية تعطي نتائج مباشرة لأسعار الأسمنت في لحظة الحاجة لتلك النتائج وذلك بمعرفة سعر الصرف الموازي للدولار مقابل

$$
\text { الجنية السوداني ومعدل التضخم. }
$$

• • المعادلة المستتبطة كذلك تمكن من قراءة وتتبع المستقبل بصورة معتدلة

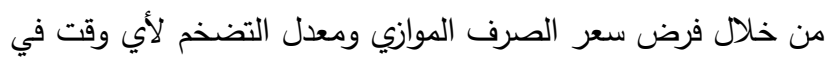
المستقبل ومن ثم استتباط أسعار المواد والبنود المتوقعة في تلك الفترة، وذلك يسهل عمليات تخطيط وإدارة المخاطر خصوصاً في المشروعات الكبيرة بالعملات المحلية.

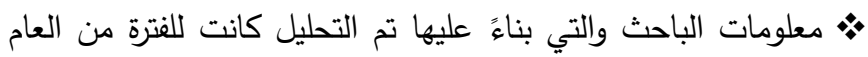
2000 وحتى العام 2016، وباستخدام المعادلات المستتبطة من التحليل الذي تم قام الباحث بحساب القيم التتبؤية للمتغيُرات وفق أسعار

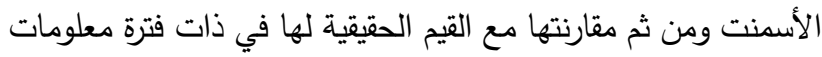
البحث (2000-2016)، وقد كانت القيم متوافقة مع ما تم الوصول إليه وأعطت قيم تقديرية قريبة جداً من الواقع وذلك باستصحاب نسب الخطأ

\begin{tabular}{|c|c|c|}
\hline التتبؤي بالمعادلة المستنبطة & سعر الأسمنت & السنوات \\
\hline 1739.73 & 3500.00 & 2017 \\
\hline 2990.18 & 6000.00 & 2018 \\
\hline 3285.98 & 10000.00 & 2019 \\
\hline
\end{tabular}

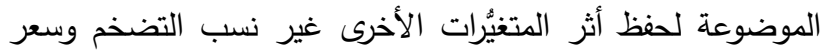
الصرف.

جدول رقم (3-5) يبين مقارنة بين القيم التتبوية وفق المعادلات المستنطة والقيم

Recommendations 5.3

من واقع الدراسة والنتائج التي تم الوصول إليها فإن الدارس يوصي بالآتي:

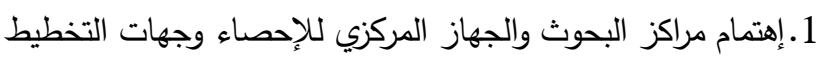
الإقتصادي بالرصد الدائم والمستمر لأسعار مواد وبنود البناء

$$
\text { والتشييد تسهيلاً لإجراء الدراسات والبحوث. }
$$




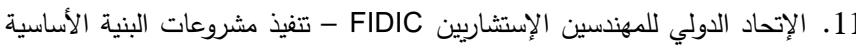

باستخدام نظام البوت والترجمة العربية لعقد فيديك الجديد الخاص بمشروعات البوت الإت الإن

(الكتاب الفضي الجديد- الطبعة الأولى: سبتمبر لتهب 1999) شروط عقد التصميم والإشتراء والتشييد/ مشروعات تسليم المفتاح.

12. د. محمد عوض رضوان - الإتجاهات الحديثة في تطوير الموازنة العامة للدولة ودورها

في إدارة البرامج والأنشطة والمشروعات الحكومية، دراسة مقارنة - الطبعة الثانية

(2009) س-نشر بواسطة دار النهضة العربية، 32 شارع عبد الخالق ثروت.

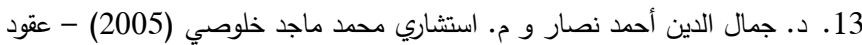

الإتحاد الدولي للمهندسين الإستشاريين FIDIC.

14. جمال الدين أحمد نصار و م. استشاري محمد ماجد خلوصي - قانون وتشريعات وعقود التشائ

الإتحاد الدولي للمهندسين الإستشاريين (فيديك).

15. بحث عن أسباب التضخم في السودان www.ahlulbaitonline.com 